\title{
Anticonvulsant, Anxiolytic and Neurotoxicity Profile of Aqarqarha (Anacyclus pyrethrum) DC (Compositae) Root Ethanolic Extract
}

\author{
Syed Mohd Abbas Zaidi ${ }^{{ }^{*}}$, Shadab Ahmad Pathan ${ }^{2}$, Surender Singh ${ }^{3}$, Shakir Jamil ${ }^{4}$, Farhan Jalees \\ Ahmad $^{2}$, Roop Krishen Khar ${ }^{2}$ \\ ${ }^{1}$ Department of Moalajat, HSZH Govt. Unani Medical College, Bhopal, India; ${ }^{2}$ Department of Pharmaceutics, Faculty of Pharmacy, \\ Jamia Hamdard, New Delhi, India; ${ }^{3}$ Department of Pharmacology, All India Institute of Medical Sciences, New Delhi, India; \\ ${ }^{4}$ Department of Moalijat, Faculty of Medicine (Unani), Jamia Hamdard \& CCRUM, New Delhi, India. \\ Email: *drsymab@gmail.com
}

Received July $27^{\text {th }}, 2013$; revised September $6^{\text {th }}, 2013$; accepted September $17^{\text {th }}, 2013$

Copyright (c) 2013 Syed Mohd Abbas Zaidi et al. This is an open access article distributed under the Creative Commons Attribution License, which permits unrestricted use, distribution, and reproduction in any medium, provided the original work is properly cited.

\begin{abstract}
Ethnopharmacological relevance: Aqarqarha (Anacyclus pyrethrum) DC root has long been used as a traditional antiepileptic remedy in Unani system of medicine over centuries. Aim of the Study: To rationalize the ethnomedical claim and screen for anxiolytic and neurotoxicity profile of ethanolic extract of Aqarqarha (Anacyclus pyrethrum) root (APE). Materials and Methods: The anticonvulsant and anxiolytic potential of APE (100 - $800 \mathrm{mg} / \mathrm{kg}$ ) was evaluated against Pentylenetetrazole (PTZ), Bicuculline (BCL), Increasing current electroshock (ICES) and Elevated plus maze(EPM) models. Rotarod test was employed as neurotoxicity model including an additional higher dose (1600 $\mathrm{mg} / \mathrm{kg})$. Results: The APE showed significant anticonvulsant activity $(\mathrm{p}<0.001)$ against PTZ $(70 \mathrm{mg} / \mathrm{kg}$, i.p. $)$ in a dose-dependent manner but against BCL (30 mg/kg, i.p.) at the dose $800 \mathrm{mg} / \mathrm{kg}$ only $(\mathrm{p}<0.001)$. However, it did not protect animals against ICES induced seizures $(\mathrm{p}>0.05)$. The extract also showed anxiolytic behaviour in EPM ( $\mathrm{p}<$ 0.001 ) and impaired motor coordination only at $1600 \mathrm{mg} / \mathrm{kg}$ in rotarod performance. HPTLC of the extract confirmed the presence of eugenol in the extract. Conclusions: The results suggested significant anticonvulsant activity of APE against PTZ and BCL but failure against ICES. Moreover, APE also exhibited anxiolytic potential without any evidence of neurotoxicity at the effective dose level. We concluded that anticonvulsant effect of APE is probably mediated by enhancing GABAergic neurotransmission.
\end{abstract}

Keywords: Aqarqarha; HPTLC; Epilepsy; Aqarqarha (Anacyclus pyrethrum)

\section{Introduction}

Epilepsy is one of the most common neurological disorders with a prevalence of 5 to 8 cases per 1000 of population in developed countries, and with even higher rates in under-developed countries [1,2]. Currently available antiepileptic drugs are synthetic compounds and have dose-related and chronic toxicity, involving virtually every major organ system, adverse effects on cognition and behavior, reduced bone mineral density and teratogenic effects [3-8]. The very high costs of the new antiepileptic drugs have a major impact on the overall cost of epilepsy therapy in both developed and underdeveloped countries [9].

${ }^{*}$ Corresponding author.
In the treasury of Unani system of medicine, there are many herbal drugs which are reported to possess antiepileptic activity and are being used by the physicians since the Stone Age. These drugs are relatively much safer as evident by their long clinical use. The root of Aqarqarha (Anacyclus pyrethrum) DC, popularly known as "Aqarqarha" in the Unani system of medicine, is reported to be used by the Unani physicians to manage, control and treat epilepsy [10,11]. It is also used to stimulate the salivary glands, cure chronic catarrh of the head and nostrils, cure toothache, improve sexual debility and clear the brain by exciting a free flow of nasal mucus, tears and by stimulating blood flow to the tissues [12]. Recently it has been found to possess immunostimulating [13] and aphrodisiac [14] action in various rodent 
models.

The herb contains an essential oil and a pungent alkaloid, pellitorin or pyrethrin. It has alkamides, lignane (including sesamine), inulin (fructosan) and tannins. Alkamides include deca-2, 4-dien acid-isobutylamide, anacycline, and dehydroanacycline $[15,16]$. The presence of a polyacetylenic compound is also reported in the root [17]. It is also reported to contain eugenol [18,19].

In an effort to scientifically validate and rationalize the medicinal value of this drug, the present study was undertaken to examine the anticonvulsant, anxiolytic and neurotoxicity profile of this herb's root ethanolic extract in various experimental paradigms.

\section{Materials and Methods}

\subsection{Plant Material}

Fresh roots of Aqarqarha (Anacyclus pyrethrum) DC (Compositae) were purchased from an authorized supplier (Green Earth Products, G.K.-1, New Delhi) which was harvested in October from the Katra region of Jammu \& Kashmir. Identification and taxonomical authentication was performed by a renowned taxonomist of NISCAIR, New Delhi and a voucher specimen no. "NISCAIR/RHMD/CONSULT/-2008-09/1099/130/Aqarqarha (Anacyclus pyrethrum)/DATE 07NOV2008” was deposited in the herbarium.

\subsection{Preparation of Aqarqarha (Anacyclus pyre- thrum) Root Ethanolic Extract (APE)}

One kilogram (1 kg) of crushed, air dried roots of Anacyclus pyrethrum was milled into a fine powder in a commercial blender. The powder was extracted twice by cold maceration on each occasion with $2.5 \mathrm{~L}$ of $99.9 \%$ ethanol for $48 \mathrm{~h}$ at room temperature, with occasional shaking. The combined extracts were concentrated to dryness under reduced pressure at $40^{\circ} \mathrm{C} \pm 1^{\circ} \mathrm{C}$ in a rotary evaporator, finally giving $35.56 \mathrm{~g}(3.556 \% \mathrm{w} / \mathrm{w}$ yield) of a dark brown, powdery crude APE. Aliquot portions of the crude APE residue were weighed and dissolved in $0.5 \% \mathrm{w} / \mathrm{v}$ Tween 80 for use on each day of our experiments.

\subsection{HPTLC Fingerprinting of the Prepared Extract}

TLC profile of the APE was developed prior to going for the HPTLC. Toluene: Ethyl acetate: Formic acid (3:2:0.5) was selected as the mobile phase in the UV-mode. The prepared extract was dissolved in ethanol and applied to the pre-coated Silica gel $60 \mathrm{~F}_{254}$ TLC plates (E. Merck) using a CAMAG Linomat IV Automatic Sample Spotter. After development in mobile phase, the plates were dried in air and scanned at $254 \mathrm{~nm}$ using a CAMAG TLC Scanner and winCATS software. Eugenol was also applied in the same manner to the HPTLC plates to find out the presence of eugenol in the extract.

\subsection{Drugs}

The drugs used were sodium valproate (Wockhardt Ltd., Mumbai, India), Pentylenetetrazole (PTZ) and Bicuculline (BCL) from Sigma Aldrich, USA. Drugs were freshly prepared by dissolving in distilled water. All i.p. injections were given in volumes of not more than 10 $\mathrm{ml} / \mathrm{kg}$ of the body weight for mice.

\subsection{Animals}

Swiss male albino mice weighing 20 - 35 g were procured from the central animal house, Jamia Hamdard, New Delhi. Animals were housed in groups of 6 per cage and maintained at $20^{\circ} \mathrm{C}-30^{\circ} \mathrm{C}$ and $50 \%-55 \%$ humidity in a natural light and dark cycle, with free access to food and water. The experiments were performed during the light cycle in awake, freely moving animals that were adjusted to laboratory conditions before proceeding with the experiments. The animals were divided into four groups of plant's extract $(100,200,400 \& 800 \mathrm{mg} / \mathrm{kg})$, reference anticonvulsant drug-treated "test", and distilled water-treated "cont rol" groups of 6 animals per group. The study was performed with prior approval of the Institutional Animal Ethics Committee (IAEC) of CPCSEA (Committee for the Purpose of Control and Supervision of Experiments on Animals) with approval reg. no. JH/CPCSEA/31-01-2000/Project no.418/2007 2010. Utmost care was taken to ensure that animals were treated in the most humane and ethically acceptable manner.

\subsection{Evaluation of Anticonvulsant Activity}

\subsubsection{PTZ and BCL Test}

Seizures were induced chemically with PTZ as described by Vohora et al. [20]. Standard convulsing agents, PTZ (70 mg/kg, i.p.), and BCL (30 mg/kg, i.p.) were used to induce convulsions in mice. Sodium valproate $(300 \mathrm{mg} /$ $\mathrm{kg}$, p.o.) was used as the reference anticonvulsant drug for comparison. In the test group, the seizures were induced after 60 min prior treatment with graded doses of the APE (100 - $800 \mathrm{mg} / \mathrm{kg}$, p.o.) and sodium valproate (300 mg/kg, p.o.). The ability of the APE to prevent the seizures or delay the latency or onset of the hind-limb tonic extensions was considered as an indication of anticonvulsant activity. The onset and duration of convulsions in the mice were noted and recorded, and percentage protection was determined. Distilled water (10 $\mathrm{ml} / \mathrm{kg}$, p.o.) treated mice were used as "control" animals. 


\subsubsection{ICES}

The ICES (Increasing Current Electroshock) test, as proposed by Kitano et al. [21] and modified by Ali et al. [22], was used to evaluate the anticonvulsant effect of the APE against generalized tonic clonic seizures. APE was administered at various dose levels $60 \mathrm{~min}$ before administering a current of $2 \mathrm{~mA}$. If HLTE was not observed with a current of $30 \mathrm{~mA}$, electroshock was terminated and this cut off current was used for the analysis.

\subsection{Elevated Plus-Maze Test}

The animals were trained before APE was administered at various dose levels (100 - $800 \mathrm{mg} / \mathrm{kg}$, p.o.) $60 \mathrm{~min}$ before they were placed on maze. To begin a test session, mice were placed on the open arm facing the center of the maze. An entry into an arm was defined as the animal placing all four paws over the line marking that area. The number of entries and the time spent in the open and closed arms were recorded during a $5 \mathrm{~min}$ test period. The percentage of open arm entries (100 × open / total entries) was calculated for each animal. Diazepam at a dose of $0.5 \mathrm{mg} / \mathrm{kg}$, i.p. was used as the standard. Every precaution was taken to ensure that no external stimuli, other than the height of the plus-maze could invoke maze anxiety.

\subsection{Rotarod Test}

The rotarod test according to Lima et al. [23] was used to determine the effect of APE on motor coordination. The trained animals were then evaluated for motor coordination at $30,60,90$, and 120 minutes after oral administration of $100,400,800,1600 \mathrm{mg} / \mathrm{kg}$ of the APE. The time each animal could walk continuously on the rod was recorded.

\subsection{Data Analysis}

The results are presented as means \pm SEM. Data were analyzed using a one-way analysis of variance (ANOVA) followed by Dunnett's test (GraphPad) at the 95\% confidence level. $\mathrm{P}$ values $<0.05$ were considered significant.

\section{Results}

\subsection{HPTLC Fingerprinting of the APE}

The HPTLC profile of the Aqarqarha (Anacyclus pyrethrum) ethanolic extract revealed the presence of six spots at Rf 0.10, 0.15, 0.27, 0.34, 0.65 and 0.92. Rf 0.65 corresponds to the Rf value of the pure eugenol applied and, therefore, confirmed the presence of eugenol in the extract (Figure 1).

\subsection{Effect of APE on PTZ-Induced Seizures}

The study shows that APE markedly increases the latency time for the onset of myoclonic jerks and clonic seizures and offered significant percentage of protection from $17 \%$ to $82 \%$ to mice against PTZ induced seizures in a dose-dependent manner as compared to control value. The latency time of standard was also increase to $98 \%$ as compared to control value and was found satisfactory significant as shown by Figures 2 and 3.

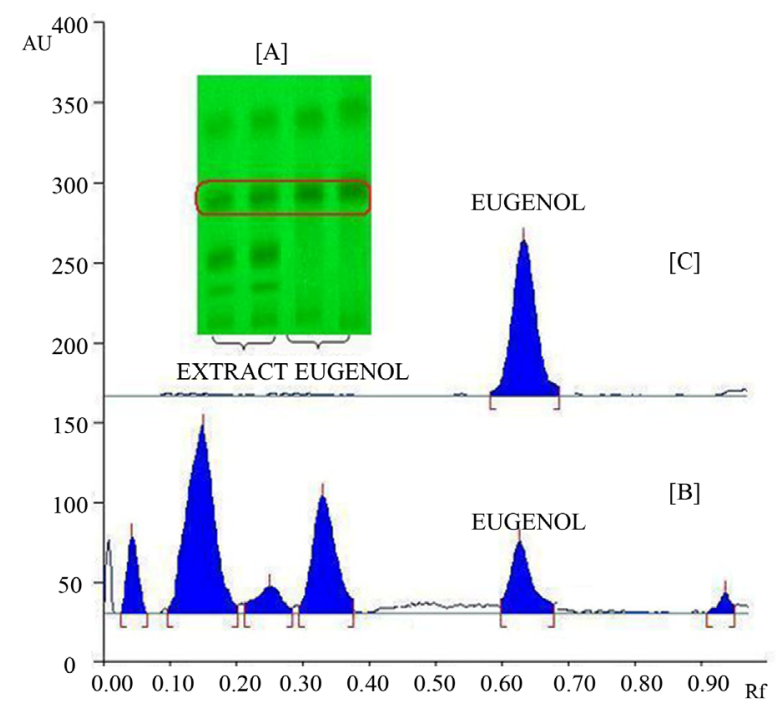

Figure 1. HPTLC fingerprinting of the Anacyclus pyrethrum ethanolic extract, [A] TLC Chromatogram of developed APE and pure eugenol; [B] HPTLC Chromatogram of extract; [C] HPTLC Chromatogram of pure Eugenol alone scanned at $254 \mathrm{~nm}$.

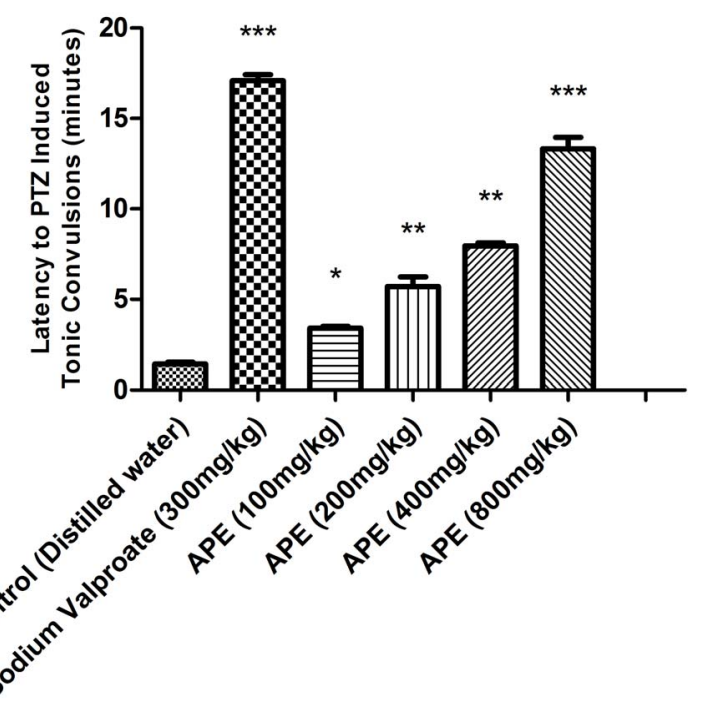

Treatment Group

Figure 2. Effect of APE and Sodium valproate on Latency against PTZ-induced seizures in mice. ${ }^{*}$ p $<0.05$; ${ }^{* *}$ p $<$ $0.01 ;{ }^{* * *} \mathrm{p}<0.001$ as compared with control group. 


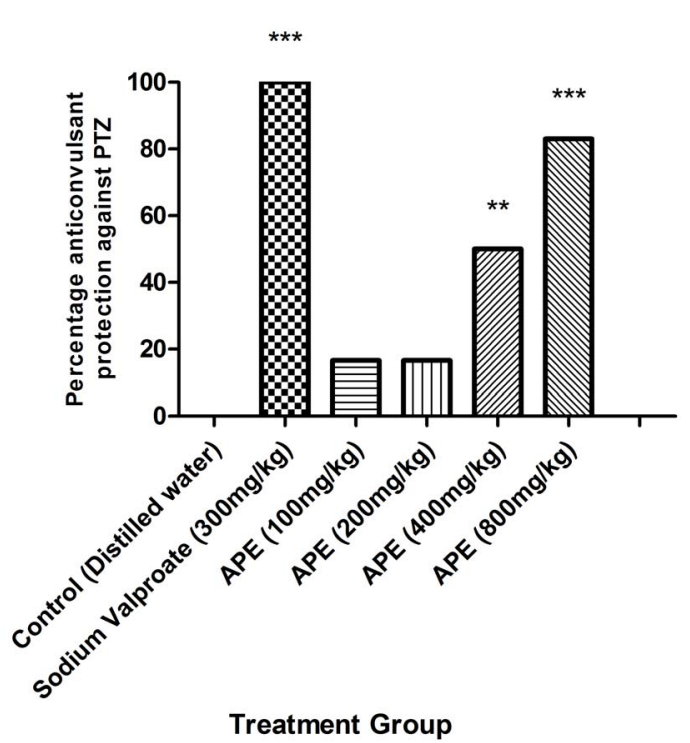

Figure 3. Percentage anticonvulsant protective effect of APE on PTZ-induced seizures in mice. ${ }^{*} \mathrm{p}<0.05 ;{ }^{* *} \mathrm{p}<0.01$ and ${ }^{* * *} \mathrm{p}<0.001$ as compared with control group.

\subsection{Effect of APE on BCL-Induced Seizures}

The study shows that $66 \%$ animals, treated with APE $(800 \mathrm{mg} / \mathrm{kg})$ produced significant protection $(\mathrm{p}<0.001)$ against BCL induced seizures, while the animals treated with lower doses of APE (100 - $400 \mathrm{mg} / \mathrm{kg}$ ) did not show any protection against BCL induced seizures. 100\% animals showed significant ( $\mathrm{p}<0.001$ ) protection against BCL induced seizures which were treated with standard (Sodium valproate). The latency of tonic convulsions was found $7.26 \%, 15.22 \% 33.91 \%$ and $227.33 \%$ increase in APE $(100-800 \mathrm{mg} / \mathrm{kg})$ treated animals and $530.79 \%$ increase in sodium valproate treated animals as shown by Figures 4 and 5.

\subsection{Effect of APE on ICES-Induced Seizures}

Aqarqarha (Anacyclus pyrethrum) root ethanolic extract (APE, $100-800 \mathrm{mg} / \mathrm{kg}$, p.o.) did not show any protective effect against ICES-induced seizures.

\subsection{Effect of APE on Elevated plus Maze}

In the elevated plus maze, the observed behavior confirmed the anxiolytic activity of diazepam as reported. The APE at the dose of $800 \mathrm{mg} / \mathrm{kg}$ increased the percentage of time spent and entries in the open arms ( $p<$ 0.001). However, APE (100 - $400 \mathrm{mg} / \mathrm{kg})$ had no significant effect on any of the measured parameters (Figures 6 and 7).

\subsection{Effect of APE on Rotarod Test}

APE did not produce the statistically significant distur-

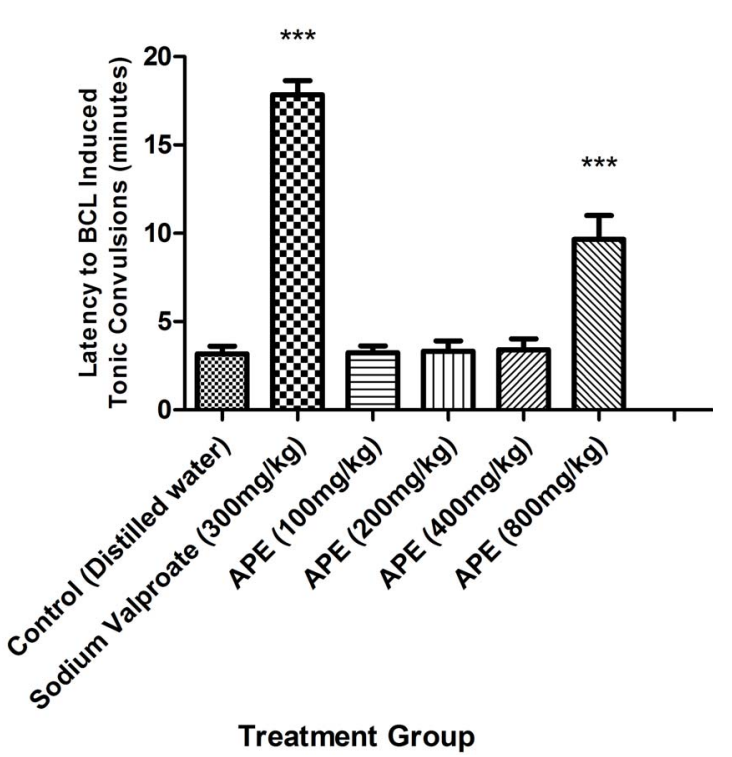

Figure 4. Effects of APE and Sodium valproate on Latency against BCL induced seizures in mice ${ }^{* * *} \mathrm{p}<0.001$ as compared with control group.

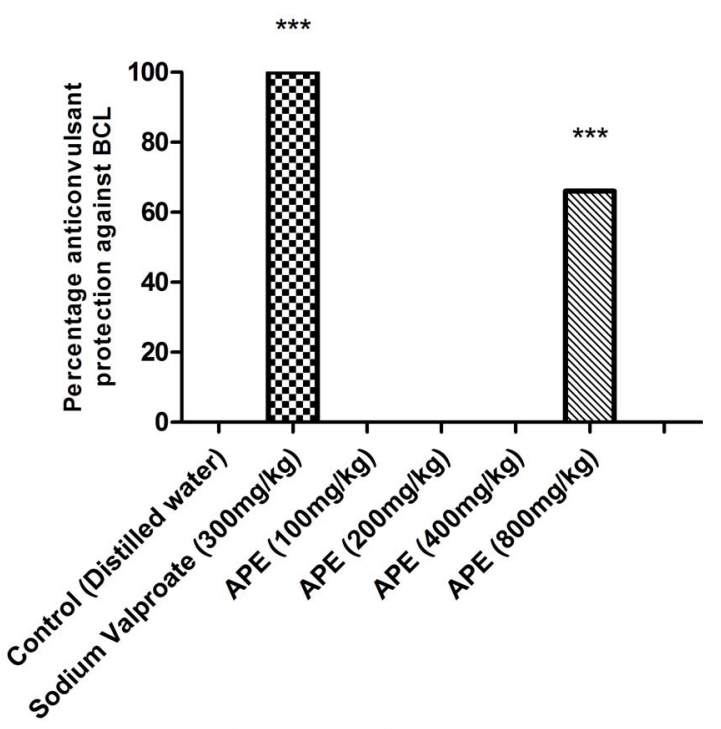

Treatment Group

Figure 5. Percentage anticonvulsant protective effect of APE against BCL-induced seizures in mice. ${ }^{* * *} \mathrm{p}<\mathbf{0 . 0 0 1}$ as compared with control group.

bance in motor coordination or fall-off time up to the maximum dose of $1600 \mathrm{mg} / \mathrm{kg}$ p.o. at $60 \mathrm{~min}$ postadministration period. However, the dose of $1600 \mathrm{mg} / \mathrm{kg}$ of APE at 90 and 120 min post administration exhibited a significant impairment in motor coordination (Figure 8).

\section{Discussion}

There are a number of synthetic anticonvulsant drugs currently available for use in the management, control 


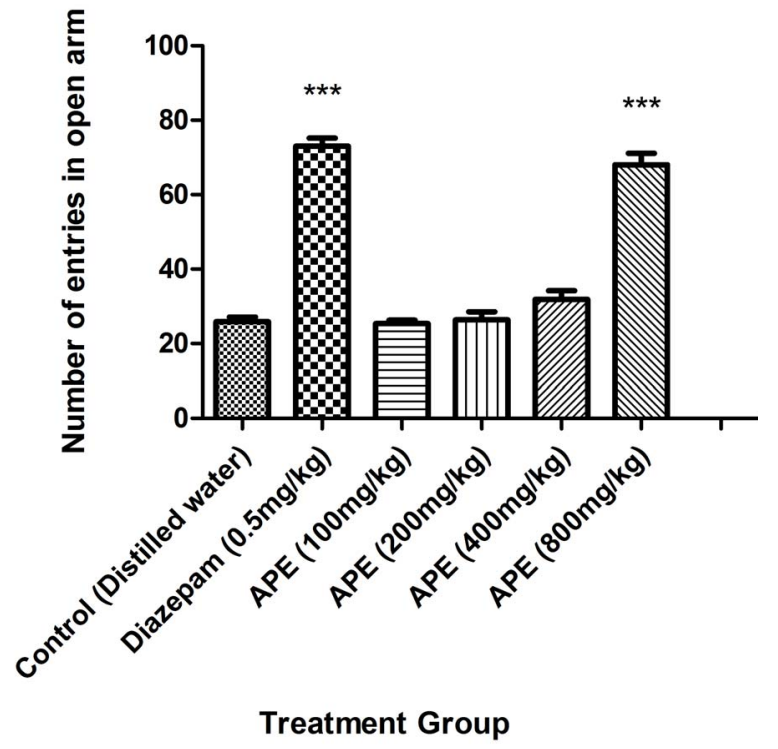

Figure 6. Number of open arm entries in Elevated plus maze. ${ }^{* * *} \mathrm{p}<0.001$ as compared with control group.

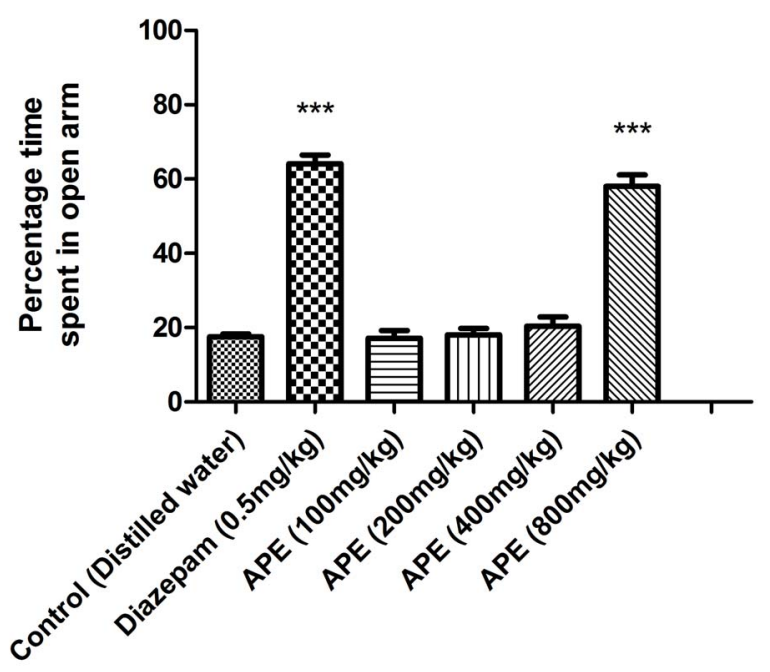

Treatment Group

Figure 7. Percentage time spent in open arm in Elevated plus maze ${ }^{* * *} \mathbf{p}<\mathbf{0 . 0 0 1}$ as compared with control group.

and/or treatment of individuals with epilepsy. Keeping in view of their inaccessibility, higher cost and increased toxicity, there is a dire need for the development of cheap, effective and relatively safer anticonvulsant agents from plants and other natural sources. Although Aqarqarha (Anacyclus pyrethrum) root is widely used by the practitioners of Unani system of medicine for epilepsy, relatively little scientific information exists in biomedical literature on the therapeutic efficacy of the plant.

The data obtained in this study also indicate that relatively moderate and high doses of APE inhibited or attenuated PTZ-induced seizures, while the reference

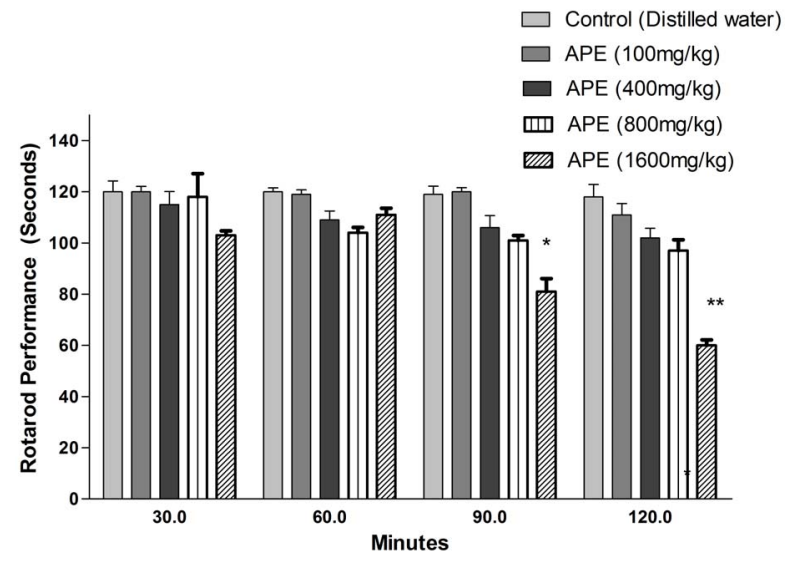

Figure 8. Effect of i.p. administration of APE on rotarod test endurance time in seconds at different time intervals: $30,60,90$, and $120 \mathrm{~min}$ post administration. ${ }^{*} \mathrm{p}<0.05$ and ${ }^{* *} \mathbf{p}<0.01$ as compared with control group.

anticonvulsant drug used, i.e. sodium valproate, completely abolished the seizures and protected all the animals against PTZ-induced seizures. PTZ has been reported to produce seizures by inhibiting gamma aminobutyric acid (GABA) neurotransmission. Favoring the GABAergic hypothesis for sodium valproate is inhibition of the onset of seizures induced by GABA antagonists [24] which selectively enhances GABAergic inhibition in the cerebral cortex [25].

It would appear, therefore, that the complete protection of the mice by the reference anticonvulsant drug used in this study against PTZ-induced seizures is in consonance with the above hypothesis. The findings of the present study, therefore, tend to suggest that APE might have inhibited and/or attenuated PTZ-induced seizures of the mice by inhibiting high-frequency firing of neurons and/or enhancing some ways interfering with GABA ergic neurotransmission.

$\mathrm{BCL}$, a potent and selective $\mathrm{GABA}_{\mathrm{A}}$-receptor antagonist, produces seizures by blocking the effect of GABA at central $\mathrm{GABA}_{\mathrm{A}}$-receptors, which have been associated with epilepsy. Sodium valproate, which also acts by enhancing GABA neurotransmission, antagonized BCLinduced seizures in the present study. However, APE only at dose $800 \mathrm{mg} / \mathrm{kg}$, antagonized BCL-induced seizures, which was less effective in this regard com- pared with Sodium valproate. This observation also tends to suggest that APE interferes with GABAergic neurotransmission. APE was also found to possess anxiolytic potential when examined on the elevated plus-maze test at the dose of $800 \mathrm{mg} / \mathrm{kg}$. The magnitude of the anxiolytic effects of this dose was very close to that observed with $0.5 \mathrm{mg} / \mathrm{kg}$ of diazepam. These anxiolytic properties could be mediated by some components in the extract interacting with the benzodiazepine/GABA $\mathrm{A}_{\mathrm{A}}$ receptors as 
agonists, with the 5- $\mathrm{HT}_{1 \mathrm{~A}}$ receptors agonists, or with any other mechanisms. Furthermore, APE did not show any neurotoxic activities at the effective anticonvulsant dose level $(800 \mathrm{mg} / \mathrm{kg})$ in the rotarod test. However, it impaired motor coordination at $1600 \mathrm{mg} / \mathrm{kg}, 90 \mathrm{~min}$ after the APE administration.

Our present state of knowledge of the chemical constituents of the extract is limited. It is, therefore, impossible for us at this stage, to pinpoint and identify with certainty, the anticonvulsant principle of the extract. Nevertheless, eugenol (4-allyl-2-methoxyphenol, $\mathrm{C}_{10} \mathrm{H}_{12} \mathrm{O}_{2}$, an aromatic terpene compound, whose presence was confirmed in the extract by HPTLC fingerprinting, is likely to account for the observed anticonvulsant activity of the APE. Szabadics and Erdelyi [26] have shown that eugenol blocks the synaptic transmission in the snail, Helix pomatia L., neurons both pre- and post-synaptically. There are some studies indicating that eugenol possesses an inhibitory effect on the events related to NMDA receptor activation and also protects neuronal cells from NMDA-induced excitotoxic and oxidative injury [27]. Furthermore, it protects hippocampal neurons from global ischemia through modulation of NMDA receptors and also delays NMDA-induced convulsions [28].

The experimental evidence obtained in the present laboratory animal study indicates that APE significantly delayed the onset of seizures induced by PTZ. Since PTZ-induced seizures have been shown to be due to the inhibition and/or attenuation of GABAergic neurotransmission, it is not unreasonable to speculate that APE probably produces its anticonvulsant activity by enhancing GABAergic neurotransmission.

In conclusion, the findings of the present laboratory animal study lend a pharmacological support to the suggested anecdotal, ethnomedical uses of Aqarqarha (Anacyclus pyrethrum) roots in the treatment of epilepsy in the Unani system of medicine. The results of the present laboratory animal study provide evidence in favor of the selective anticonvulsant activity of the herb, and show that APE also possesses significant anxiolytic activity without evidence of any neurotoxicity at the effective dose level used. The effectiveness of the plant's extract in the experimental convulsion paradigm used probably suggests that the herb could be used in complex partial and absence types of epilepsy as supported by its failure to protect the animals against ICES test. However, extensive studies are needed to evaluate the precise mechanism(s) of the plant as a medicinal remedy for epilepsy.

\section{Acknowledgements}

Authors are highly thankful to Dr Shadab Zafar (Medical
Officer, Municipal Corporation of Delhi) for his useful suggestions.

\section{REFERENCES}

[1] J. W. Sander and S. D. Shorvon, "Epidemiology of the Epilepsies," Journal of Neurology Neurosurgery \& Psychiatry, Vol. 61, No. 5, 1996, pp. 433-443. http://dx.doi.org/10.1136/jnnp.61.5.433

[2] N. Senanayake and G. C. Roman, "Epidemiology of Epilepsies in Developing Countries,” WHO Bulletin, Vol. 71, No. 2, 1993, pp.247-258

[3] O. Devinsky, "Cognitive and Behavioral Effects of Antiepileptic Drugs,” Epilepsia, Vol. 36, Suppl. s2, 1995, pp. S46-S65. http://dx.doi.org/10.1111/j.1528-1157.1995.tb05999.x

[4] G. L. Holmes, "Critical Issues in the Treatment of Epilepsy,” American Journal of Hospital Pharmacist, Vol. 50, Suppl. 5, 1993, pp. S5-S16.

[5] R. H. Mattson, "Efficacy and Adverse Effects of Established and New Antiepileptic Drugs,” Epilepsia, Vol. 36, Suppl. S2, 1995, S13- S26.

http://dx.doi.org/10.1111/j.1528-1157.1995.tb05995.x

[6] E. B. Samren, C. M. V. Duijn, G. C. M. L. Christiaens, A. Hofman and D. Lindhout, "Antiepileptic Drug Regimens and Major Congenital Abnormalities in the Offspring," Annals of Neurology, Vol. 46, No. 5, 2001, pp. 739-746. http://dx.doi.org/10.1002/1531-8249(199911)46:5<739:: AID-ANA9>3.0.CO;2-2

[7] M. C. Smith and T. P. Bleck, "Convulsive Disorders: Toxicity of Anticonvulsants," Clinical Neuropharmacology, Vol. 14, No. 2, 1991, pp. 97-115. http://dx.doi.org/10.1097/00002826-199104000-00001

[8] I. I. Ali, L. Schuh, G. L. Barkley and J. R. Gates, "Antiepileptic Drugs and Reduced Bone Mineral Density," Epilepsy \& Behavior, Vol. 5, No. 3, 2004, pp. 296-300. http://dx.doi.org/10.1016/j.yebeh.2004.02.005

[9] D. Heaney, "The Pharmacoeconomics of the New Antiepileptic Drugs,” Epilepsia, Vol. 40, Suppl. s8, 1999, pp. 25-31. http://dx.doi.org/10.1111/j.1528-1157.1999.tb00944.x

[10] Z. Razi, “Al-Hawi-Fil-Tib (Urdu Translation),” CCRUM Publication, New Delhi, 1997.

[11] I. Baitar, “Al-Jam-e-ul-Mufradat-Al-Adviah-Wal-Aghziya (Urdu translation),” CCRUM publication, New Delhi, 1999.

[12] N. G. Khan, "Khazainul Adviah,” Matba Munshi Naval Kishore, Lucknow, 1921.

[13] D. Bendjeddou, K. Lalaoui and D. Satta, "Immunostimulating Activity of the Hot Water-Soluble Polysaccharide Extracts of Anacyclus pyrethrum, Alpinia galanga and Citrullus colocynthis," Journal of Ethnopharmacology, Vol. 88, No. 2-3, 2003, pp. 155-160. http://dx.doi.org/10.1016/S0378-8741(03)00226-5

[14] V. Sharma, M. Thakur, N. S. Chauhan and V. K. Dixit, "Evaluation of the Anabolic, Aphrodisiac and Reproduc- 
tive Activity of Anacyclus pyrethrum DC in Male Rats," Scientia Pharmaceutica, Vol. 77, 2009, pp. 97-110. http://dx.doi.org/10.3797/scipharm.0808-14

[15] J. M. Gulland and G. U. Hopton, "Pellitorine, the Pungent Principle of Anacyclus pyrethrum," Journal of Chemical Society, 1930, pp. 6-11. http://dx.doi.org/10.1039/jr9300000006

[16] R. S. Burden and L. Crombie, "Amides of Vegetable Origin. Part XII. A New Series of Alka-2, 4-Dienoic Tyramine-Amides from Anacyclus pyrethrum D. C. (Compositae)," Journal of the Chemical Society C: Organic, No. 19, 1969, pp. 2477-2481. http://dx.doi.org/10.1039/j39690002477

[17] “The Wealth of India," CSIR Publication, New Delhi, 1985.

[18] K. Sukumaran and R. Kuttan, "Inhibition of TobaccoInduced Mutagenesis by Eugenol and Plant Extracts," Mutation Research/Genetic Toxicology, Vol. 343, No. 1, 1995, pp. 25-30. http://dx.doi.org/10.1016/0165-1218(95)90059-4

[19] A. Gorji and M. K. Ghadiri, "History of Epilepsy in Medieval Iranian Medicine,” Neuroscience \& Biobehavoiral Reviews, Vol. 25, No. 5, 2001, pp. 455-461. http://dx.doi.org/10.1016/S0149-7634(01)00025-2

[20] D. Vohora, S. N. Pal and K. K. Pillai, “Thioperamide a Selective Histamine H3 Receptor Antagonist, Protects Against PTZ-Induced Seizures in Mice,” Life Science, Vol. 66, No. 22, 2000, pp. 297-301. http://dx.doi.org/10.1016/S0024-3205(00)00548-8

[21] Y. Kitano, C. Usui, K. Takasuna, M. Hirohashi and M. Nomura, "Increasing-Current Electroshock Seizure Test: A New Method for Assessment of Anti- and Pro-Convulsant Activities of Drugs in Mice," Journal of Pharmacological and Toxicological Methods, Vol. 35, No. 1, 1996, pp. 25-29. http://dx.doi.org/10.1016/1056-8719(95)00115-8
[22] A. Ali, F. J. Ahmad, K. K. Pillai and D. Vohora, "Evidence of the Antiepileptic Potential of Amiloride with Neuropharmacological Benefits in Rodent Models of Epilepsy and Behavior,” Epilepsy \& Behaviour, Vol. 5, No. 3, 2004, pp. 322-328. http://dx.doi.org/10.1016/j.yebeh.2004.01.005

[23] T. C. M. Lima, G. S. Morato and R. N. Takahashi, "Evaluation of the Control Properties of Artemisia Verloturum,” Planta Medica, Vol. 59, No. 4, 1993, pp. 326-329. http://dx.doi.org/10.1055/s-2006-959692

[24] H. H. Frey and W. Loscher, "Di-n-Propyletic Acid-Profile of Anticonvulsant Activity in Mice,” Arzneimittelforschung, Vol. 26, 1976, pp. 299-301.

[25] F. Baldino and H. M. Geller, "Sodium Valproate Enhancement of Gamma-Aminobutyric Acid (GABA) Inhibition: Electro-Physiological Evidence for Anticonvulsant Activity," The Journal of Pharmacology and Experimental Therapeutics, Vol. 217, No. 2, 1981, pp. 445-450.

[26] J. Szabadics and L. Erdelyi, "Pre- and Postsynaptic Effect of Eugenol and Related Compounds on Helix pomatia L. Neurons,” Acta Biologica Hungarica, Vol. 51, No. 2-4, 2000, pp. 265-273.

[27] M. B. Wie, M. H. Won, K. H. Lee, J. H. Shin, J. C. Lee, H. W. Suh, D. K. Song and Y. H. Kim, "Eugenol Protects Neuronal Cells from Excitotoxic and Oxidative Injury in Primary Cortical Cultures," Neuroscience Letters, Vol. 225, No. 4, 1997, pp. 93-96. http://dx.doi.org/10.1016/S0304-3940(97)00195-X

[28] M. H. Won, J. C. Lee, Y. H. Kim, D. K. Song, H. W. Suh, Y. S. Oh, J. H. Kim, T. K. Shin, Y. J. Lee and M. B. Wie, "Post-Ischemic Hypothermia Induced by Eugenol Protects Hippocampal Neurons from Global Ischemia in Gerbils,” Neuroscience Letters, Vol. 254, No. 2, 1998, pp. 101-104. http://dx.doi.org/10.1016/S0304-3940(98)00664-8 